\title{
Perceived Similarity to Gender Groups Scale: Validation in a Sample of Italian LGB + and Heterosexual Young Adults
}

\author{
Roberto Baiocco ${ }^{1}$ (D) Chiara Antoniucci ${ }^{1} \cdot$ Emanuele Basili $^{2} \cdot$ Jessica Pistella ${ }^{1} \cdot$ Ainzara Favini $^{2} \cdot$ Carol Martin $^{3}$. \\ Concetta Pastorelli
}

Accepted: 26 July 2021 / Published online: 4 August 2021

(c) The Author(s) 2021

\begin{abstract}
Introduction The present article describes two interrelated studies that examine gender typicality in young adulthood using a new dual-identity approach.

Methods Participants were recruited online from March 2020 to February 2021 and reported their perceived similarity to own- and other-gender peers as a way to assess their gender typicality. In study 1, the authors conducted an exploratory factor analysis (EFA) and a confirmatory factor analysis (CFA) to test and validate the Perceived Similarity to Gender Groups Scale in a sample of Italian young adults $\left(n=571 ; M_{\text {age }}=23.9 ; \mathrm{SD}=3.60\right)$. The authors documented the configural, metric, scalar measurement invariance, and validity. In study 2, the Perceived Similarity to Gender Groups Scale adopted in study 1 was used to assess the distribution of different typologies of gender typicality in another sample of Italian young adults who vary in gender and sexual orientation $\left(n=1126 ; M_{\mathrm{age}}=24.3 ; \mathrm{SD}=3.51\right)$.

Results Results confirmed the structural validity of the Perceived Similarity to Gender Groups Scale, revealing the two-factor structure of the scale. Moreover, results of cluster analysis found different typologies of self-perceptions of gender typicality. Conclusion Both studies emphasize the relevance of studying gender typicality in young adulthood through a dual-identity approach, highlighting the relevance of gender and sexual orientations.
\end{abstract}

Policy Implications The use of the dual-identity approach has significant social and clinical implications as it represents a more flexible and representative model of the complexity of gender typicality.

Keywords Gender typicality · Gender similarity $\cdot$ Sexual orientation $\cdot$ Young adulthood $\cdot$ Gender development $\cdot$ Dual identity

\section{Introduction}

Gender typicality refers to individuals' perceptions of how typical they believe they are for their gender group across a range of interests, behaviors, activity levels, and the way of interacting with other people (Egan \& Perry, 2001; Martin et al., 2017a, b). Recent years have seen significantly

Roberto Baiocco

roberto.baiocco@uniroma1.it

1 Department of Developmental and Social Psychology, Faculty of Medicine and Psychology, Sapienza University of Rome, Rome, Italy

2 Department of Psychology, Faculty of Medicine and Psychology, Sapienza University of Rome, Rome, Italy

3 School of Social and Family Dynamics, Arizona State University, Tempe, AZ, USA increased interest in understanding the relation between gender typicality and young adults' mental health and behavior (Bukowski et al., 2019). Also, a new, expanded method of assessing gender typicality was recently proposed-a dual-identity approach-in which two types of typicality (called "similarity") were assessed: feeling similar to one's own gender and feeling similar to the other gender (Martin et al., 2017a). The dual-identity approach has been explored among children in the United States (Martin et al., 2017a, b) and young adults in the United States (Andrews et al., 2019) and in the Netherlands (Endendijk et al., 2019). Using samples of young adult participants, the goals of the current two studies were the following: study 1: to examine the psychometric properties of the Perceived Similarity to Gender Groups Scale (Martin et al., 2017a) by investigating dimensions of own- and other-gender similarity and to explore how these dimensions of gender similarity relate to psychological 
outcomes; study 2: to investigate the distribution of individuals by gender and sexual orientation in four typologies created from these two dimensions of gender similarity.

Researchers interested in children's development have described gender identity as a multidimensional construct in which gender typicality is a central component (Braun \& Davidson, 2017; Carver et al., 2003; DiDonato et al., 2012; Egan \& Perry, 2001; Nielson et al., 2020; Pauletti et al., 2017; Smith \& Leaper, 2006; Young \& Sweeting, 2004). Despite different studies that examined self-perceptions of gender typicality, the ways it has been theorized and investigated differ. Primary studies considered gender typicality as a single bipolar dimension in which typicality to own gender and typicality to other gender were opposite poles of a continuum (Egan \& Perry, 2001).

However, there is a rich theoretical tradition that considered aspects of masculinity and femininity to be two different and independent dimensions: People can identify themselves with one, both, or neither of them, thereby allowing a more nuanced view of what might be considered typical of each gender (Bem, 1981;1985; Costantinopole, 1973; Spence et al., 1975). In line with Bem's theory, the "dual-identity" approach proposed by Martin and colleagues (2017a, b) represented a new method for measuring gender typicality in which similarity to own gender and similarity to other gender are viewed as independent dimensions, and using these dimensions, individuals can be meaningfully grouped into diverse typologies with different relations to well-being and adjustment. As a result of this conceptualization and measurement of dual identities, four different typologies of children were found to be (a) own-gender similarity (high levels of own-gender similarity and low levels of other-gender similarity); (b) other-gender similarity (high levels of othergender similarity and low levels of own-gender similarity); (c) both-gender similarity (high levels of own-gender similarity and high levels of other-gender similarity), and (d) lowgender similarity (low levels of own-gender similarity and low levels of other-gender similarity).

Recently, this new approach and measure of gender typicality proposed by Martin and colleagues (2017) was adapted and validated in young adulthood (Andrews et al., 2019; Endendijk et al., 2019). In general, young adulthood is a critical life stage for identity construction and definition and gender identity development (Arnett, 2000; Barret \& White, 2002; DiDonato et al., 2012; Leaper \& Van, 2008; Lefkowitz \& Zeldon, 2006). In these new studies, adults showed less gender similarity to their own gender, and they were more able to identify themselves with other gender than were school-aged children (Andrews et al., 2019; Endendijk et al., 2019). These results are in line with the cognitivedevelopmental perspective (Erikson, 1968; Kohlberg, 1966), which predicts that adults will show a more flexible perception of one's own gender thanks to the increased cognitive complexity and perspective-taking as compared to children and adolescents (Barret \& White, 2002; Marcell et al., 2011).

\section{Gender Similarity: Gender and Sexual Orientation Make a Difference}

Gender differences in self-perceived gender typicality were well-documented in literature both in childhood (Doescher \& Sugawara, 1990; Egan \& Perry, 2001; Jewell \& Brown, 2014; Menon, 2011; Menon \& Hannah-Fisher, 2019; Nielson et al., 2020; Smith \& Leaper, 2006; Tam \& Brown, 2020; Zosuls et al., 2016) and in young adulthood (Andrews et al., 2019; DiDonato \& Berenbaum, 2013; Endendijk et al., 2019; Lefkowitz \& Zeldow, 2006) reporting that females showed more flexible attitudes concerning othergender similarity compared to males (Andrews et al., 2019; DiDonato et al., 2012; Endendijk et al., 2019; Martin et al., 2012, 2017a, b; Zosuls et al., 2016). Furthermore, studies have investigated the relationship between gender typicality, well-being, academic achievement, and psychosocial adjustment, taking into account gender differences (Carver et al., 2003; DiDonato \& Berenbaum, 2013; Egan \& Perry, 2001; Jewell \& Brown, 2014; Lee \& Troop-Gordon, 2011; Mehta et al., 2017; Menon \& Hannah-Fisher, 2019; Nielson et al., 2020; Ueno \& McWilliams, 2010; Yavorsky \& Buchmann, 2019). Literature suggests that feeling typical of one's own gender relates to more gender-typed attitudes, whereas feeling typical of both genders relates to more egalitarian gender attitudes, both in females and males (Andrews et al., 2019; Dinella et al., 2014; Endendijk et al., 2019). Moreover, different studies analyzed the relation between gendertypical behaviors and academic achievement, reporting that adolescents with gender-atypical behaviors have higher academic performance than gender-typical adolescents, especially males (Leaper et al., 2012; Yavorsky \& Buchmann, 2019). Regarding sexism, research suggests that males who feel typical of both genders report less sexist beliefs than males who mainly feel typical of their own gender (Andrews et al., 2019; Pauletti et al., 2017). Interestingly, sexist attitudes are found across the spectrum of sexual orientation. The research focused on the relationship between sexism and sexual orientation has suggested that sexual minority people internalize sexist attitudes from a patriarchal society, regardless of their self-interest, attitudes, and behaviors (Cowie et al., 2019; Hässler et al., 2021; Salvati et al., 2018). Additionally, relations with adjustment have been found using gender similarity: Young adults who felt similar to their own gender reported lower social anxiety than other groups (Andrews et al., 2019). In contrast, adults and males who are less typical to their own gender reported 
the highest level of internalizing problems and externalizing problems, respectively (Endendijk et al., 2019).

Moreover, another line of research has investigated the relationship between gender atypicality and sexual orientation, supporting the hypothesis that lesbian women and gay men are, on average, more gender nonconforming in their interests, appearance, gender-typed behaviors, and feelings, compared to heterosexual women and men, and these patterns hold from childhood through adulthood (Bailey \& Zucker, 1995; Dunne et al., 2000; Lippa, 2002, 2008). For instance, Ueno and colleagues (2013) found that gay men, lesbian women, and bisexual people (LGB) tended to have more gender-atypical occupations than heterosexual participants. Green and colleagues (2018) found that LGB adults showed a mixed pattern of gender-atypical self-ratings (e.g., emotional responding, sports interests, interpersonal style, hobbies, and appearance) compared to heterosexual people during their remembered childhoods and in adulthood. A recent study, using photographs in which participants were asked to judge the target's perceived sexual orientation, happiness, anger, masculinity, or femininity, found that gender typicality facilitates accurate impressions of sexual orientation from both men's and women's faces: Less gendertypical individuals were rated as and were found to be more likely gay and lesbian (Bjornsdottir \& Rule, 2020).

Research also suggests a complex interaction between gender nonconformity and sexual orientation in predicting psychosocial distress in sexual minority people and in predicting negative attitudes toward LGB people with gender conforming and nonconforming behaviors (Green et al., 2018; Lippa, 2008; Rieger \& Savin-Williams, 2012; Salvati et al., 2018). There are two main limitations that constrain understanding of these relationships: (1) studies often used a retrospective approach to investigate the perception of gender typicality in sexual minority people (i.e., recalled childhood gender nonconformity measures, which may be inaccurate); and (2) there has been a limited view of gender typicality in understanding the psychosocial functioning of sexual minority adults. Therefore, the overarching goal of the present research is to assess the usefulness of employing a dual-identity approach to assess gender typicality in young adults varying in gender and sexual orientation. The primary purpose of the first study was to validate a measurement scale that aims to capture gender typicality in a sample of young Italian adults who vary in gender and sexual orientation. To accomplish this goal, we evaluated the psychometric properties of the Italian version of the Perceived Similarity to Gender Groups Scale (Martin et al., 2017a) by investigating dimensions of own- and other-gender similarity (Andrews et al., 2019; Endendijk et al., 2019; Martin et al., 2017a, 2017b) and to assess validity by correlating these dimensions with a variety of constructs. Specifically, we included a measure of sexism to assess the validity, and we included several other scales (i.e., self-criticism and life satisfaction) to explore correlations with the two dimensions of similarity. We expect that sexism will relate to own-gender similarity, self-criticism may relate to other-gender similarity, and we will explore relations with life satisfaction.

In the second study, the Perceived Similarity to Gender Groups Scale adopted from study 1 was used to identify gender-identity typologies among another sample of young Italian adults. We investigated the prevalence and distribution of the identified typologies in the sample, examining their relations to gender and sexual orientation. Specifically, we hypothesized that (1) male participants, regardless of sexual orientation, will report a higher level of similarity to own gender than female participants; (2) consistent with previous studies about gender atypicality and sexual orientation, we expect that, regardless of gender, heterosexual participants will report a higher level of similarity to own gender than will sexual minority participants (Bjornsdottir \& Rule, 2020; Green et al., 2018; Lippa, 2002;2008); (3) we predicted that women, regardless of sexual orientation, will be more represented in both- and other-gender identity typologies compared to men (Andrews et al., 2019); and (4) we expected that lesbian, gay, bisexual, and all other sexual orientations $(\mathrm{LGB}+)$ with which persons may identify will report feeling more similar to the other-gender group identity typologies than heterosexual individuals. Finally, considering the paucity of studies investigating gender typicality through a dual-identity approach, we did not hypothesize differences in both- and low-gender typologies depending on sexual orientations.

\section{Study 1}

\section{Method}

\section{Procedures}

Participants were recruited through online advertisements and an Internet-based survey (hosted by Unipark). Participants were recruited from community recreational centers, universities, and workplaces in Rome, Italy. Since the sexual minority participants were only $10 \%$ of the initial sample, other advertisements posted on social networks were directed toward recruiting LGB + people. Participants were not compensated, and participation in the study was voluntary and anonymous. Participants were given $20-25$ min to complete the online survey.

Informed consent was obtained from all participants, and those who accepted to take part in the study were given a link to access an Internet-based survey. To meet the inclusion criteria, participants had to (a) self-identified as a sexual minority or heterosexual person, (b) self-identified as a 
cisgender person, and (c) be of Italian nationality. Based on these criteria, 2 participants were excluded because their nationality was not Italian, and 5 were removed because they self-identified as transgender people. The other 6 participants were not included because they selected "other gender identity," but they did not specify their identity in the box provided. A total of $99 \%$ of distributed questionnaires were completely filled in. Before the data collection begun, the research protocol was approved by the Ethics Commission of the Department of Developmental and Social Psychology of the Sapienza University of Rome (Italy). All procedures performed with human participants were conducted following the ethical standards of the institutional and/or national research committee and with the 1964 Helsinki declaration.

\section{Participants}

The final sample consisted of 571 (62.9\% females; $0.4 \%$ intersex) Italian participants with ages ranging from 18 to 32 years $\left(M_{\mathrm{age}}=23.9, \mathrm{SD}=3.60\right)$. Biological sex was evaluated by the item: "What is your biological sex?" Response options included $1=$ female, $2=$ male, and $3=$ intersex. One participant $(0.2 \%)$ self-identified as intersex, and we did not include this respondent in the final sample. The sample included individuals who self-identified as heterosexual people $(54.8 \%, n=313 ; 59.4 \%$ women), bisexual people $(17.5 \%, n=100 ; 96 \%$ women), gay men $(13.8 \%, n=79)$, lesbian women $(9.8 \%, n=56)$, and other non-heterosexual people (i.e., same-gender-loving, men who have sex with men, women who have sex with women, bi-curious, and questioning; $4 \%, n=23$; $91 \%$ women). The ANOVA conducted on age showed that in the present sample, the sexual minority people were younger than the heterosexual people $(F(1,569)=12.590, p<.001)$. The general level of education was medium to high, with 142 participants (24.9\%) having at least a university degree and 128 participants (22.4\%) having completed secondary school. Concerning socioeconomic status, the majority of individuals, 418 participants $(73.2 \%)$, reported an average status, whereas 107 (18.7\%) reported a below-average status, and $46(8.1 \%)$ declared an above-average status. Demographic distributions are shown in Table 1.

\section{Measures}

\section{Perceived Similarity to Gender Groups Scale}

Similarity to own-gender and other-gender peers was assessed using Martin and colleagues' measure (2017a). Participants responded to 10 items indicating how similar they felt to both men and women (e.g., "How similar do you feel to [females/males]?"). Responses ranged from 0 (not similar at all) to 4 (very similar). The original scale presents

Table 1 Sample demographics

\begin{tabular}{|c|c|c|c|c|c|c|}
\hline & \multicolumn{2}{|c|}{$\begin{array}{l}\text { Total sample } \\
N=571 \\
(100 \%)\end{array}$} & \multicolumn{2}{|c|}{$\begin{array}{l}\text { Heterosexual } \\
N=313 \\
(54.8 \%)\end{array}$} & \multicolumn{2}{|c|}{$\begin{array}{l}\mathrm{LGB}+ \\
N=258 \\
(45.2 \%)\end{array}$} \\
\hline & $N$ & $\%$ & $N$ & $\%$ & $N$ & $\%$ \\
\hline \multicolumn{7}{|l|}{ Education } \\
\hline Middle school diploma & 29 & 5.1 & 9 & 2.9 & 20 & 7.7 \\
\hline High school diploma & 272 & 47.6 & 131 & 41.8 & 141 & 54.7 \\
\hline Bachelor's degree & 128 & 22.4 & 80 & 25.6 & 48 & 18.6 \\
\hline Master's degree & 122 & 21.4 & 83 & 26.5 & 39 & 15.1 \\
\hline Postgraduate level & 20 & 3.5 & 10 & 3.2 & 10 & 3.9 \\
\hline \multicolumn{7}{|l|}{ SES } \\
\hline Extremely low & 7 & 1.2 & 5 & 1.6 & 2 & 0.8 \\
\hline Low & 100 & 17.5 & 47 & 15.0 & 53 & 20.5 \\
\hline Average & 418 & 73.2 & 237 & 75.7 & 181 & 70.2 \\
\hline High & 44 & 7.7 & 23 & 7.4 & 21 & 8.1 \\
\hline Extremely high & 2 & 0.4 & 1 & 0.3 & 1 & 0.4 \\
\hline \multicolumn{7}{|l|}{ Relationship status } \\
\hline Single & 273 & 47.8 & 128 & 40.9 & 145 & 56.2 \\
\hline Engaged (not cohabiting) & 210 & 36.8 & 134 & 42.8 & 76 & 29.4 \\
\hline Cohabiting & 60 & 10.5 & 34 & 10.9 & 26 & 10.1 \\
\hline Civil union & 2 & 0.3 & 0 & 0 & 2 & 0.8 \\
\hline Married & 16 & 2.8 & 13 & 4.1 & 3 & 1.2 \\
\hline Other & 10 & 1.8 & 4 & 1.3 & 6 & 2.3 \\
\hline
\end{tabular}


a two-factor solution in which similarity to female gender (SFG) and similarity to male gender (SMG) are distinct.

\section{Ambivalent Sexism Inventory (ASI)}

Participants completed the 12-item short versions of the Ambivalent Sexism Inventory (Glick \& Fiske, 1996; Rollero et al., 2014) and were asked to indicate their agreement or disagreement with each statement on a 0 (strongly disagree) to 5 (strongly agree) scale (sample item, "The world would be a better place if women supported men more and criticized them less"). The items were averaged to a total score, with higher scores indicating a higher level of sexism. Scale descriptives and reliabilities are presented in Table 2.

\section{Self-Criticizing/Attacking Scale}

An 8-item version of the Self-Criticizing/Attacking Scale (Gilbert et al., 2004) was used for the present study. To a first probe statement: "When things go wrong for me...." and then either an attacking response to the probe that participants responded to using a 5-point Likert scale ranging from 0 (not at all like me) to 4 (extremely like me). Two subscales were considered in the present study: (1) the Hated Self subscale, which captures a more destructive, disgust-based response to setbacks characterized by self-dislike and an aggressive desires toward the self (sample item, "I have a sense of disgust with myself") and the (2) Inadequate Self subscale that taps to a sense of feeling of being inadequate facing failures and setbacks (sample item, "I am easily disappointed with myself"). Both subscales showed good reliabilities (see Table 2 for descriptives and reliabilities).

\section{Satisfaction with Life Scale (SWLS)}

The Satisfaction with Life Scale (Diener et al., 1985) comprises 5 items used to measure one's global satisfaction with life. Each item is rated on a seven-point scale from 1 (strongly disagree) to 7 (strongly agree) (sample item, "If could live my life over, I would change almost nothing"). The results of the five items were summed to produce an overall score that showed good reliability (see Table 2 for descriptives and reliabilities).

\section{Data Analytic Plan}

To test and validate the structure of the Perceived Similarity to Gender Groups Scale in the Italian sample, we conducted exploratory factor analysis (EFA) and confirmatory factor analysis (CFA). The total sample was randomly split into two sub-samples (calibration sample, $n=181$, for the EFA; validation sample, $n=390$, for the CFA) using the SPSS random split routine. The data were normally distributed for both calibration and validation samples. One-way ANOVAs were conducted on the two samples to test for significant differences in participants' demographic characteristics. Results showed no significant differences regarding gen$\operatorname{der}(F=0.22 ; p=0.88)$, age $(F=2.56 ; p=0.11)$, education $(F=0.19 ; p=0.66)$, and income $(F=0.00 ; p=0.99)$. Analyses were conducted using Mplus 7 (Muthén \& Muthén, 2012). A series of EFAs were conducted on the 10 items to ascertain the goodness of the hypothesized 2-factor solution of the Perceived Similarity to Gender Groups Scale (i.e., SFG and SMG) against possible alternative models (i.e., 1and 3-factor solutions) and select the items with the best psychometric properties. High primary standardized factor loadings were defined as above 0.40 , and cross-loadings were defined as having a value $\geq 0.32$ (Tabachnick \& Fidell, 2013).

Following the EFA, a CFA was conducted on the validation sample to cross-validate the number of factors that emerged from the EFA. Both EFA and CFA models were tested using a maximum likelihood estimator (Kim \& Yoon, 2011). Data fit was evaluated through standard fit indices including $\chi^{2}$, comparative fit index (CFI), root mean square error of approximation (RMSEA), and standardized

Table 2 Descriptive (means, standard deviations, alphas) of the sample's scales, divided by gender and sexual orientation

\begin{tabular}{|c|c|c|c|c|c|c|c|c|c|c|}
\hline & \multicolumn{2}{|c|}{$\begin{array}{l}\text { Total sample } \\
N=571(100 \%)\end{array}$} & \multicolumn{2}{|c|}{$\begin{array}{l}\text { Men } \\
N=212(37.1 \%)\end{array}$} & \multicolumn{2}{|c|}{$\begin{array}{l}\text { Women } \\
N=359(62.9 \%)\end{array}$} & \multicolumn{2}{|c|}{$\begin{array}{l}\text { Heterosexual } \\
N=331 \\
(54.8 \%)\end{array}$} & \multicolumn{2}{|l|}{$\begin{array}{l}\mathrm{LGB}+ \\
N=258 \\
(45.2 \%)\end{array}$} \\
\hline & $M(\mathrm{SD})$ & $\alpha$ & $M(\mathrm{SD})$ & $\alpha$ & $M(\mathrm{SD})$ & $\alpha$ & $M(\mathrm{SD})$ & $\alpha$ & $M(\mathrm{SD})$ & $\alpha$ \\
\hline Own-gender typicality & $2.48(.83)$ & .85 & $2.25(.85)$ & .78 & $2.45(.82)$ & .81 & $2.74(.78)$ & .88 & $2.18(.78)$ & .78 \\
\hline Other-gender typicality & $1.53(.78)$ & .83 & $1.43(.83)$ & .86 & $1.59(.75)$ & .73 & $1.34(.76)$ & .87 & $1.75(.74)$ & .75 \\
\hline ASI & $2.28(.92)$ & .89 & $2.59(.90)$ & .85 & $2.10(.88)$ & .90 & $2.64(.91)$ & .87 & $1.85(.72)$ & .86 \\
\hline Hated self & $2.14(1.00)$ & .81 & $1.93(.88)$ & .77 & $2.27(1.05)$ & .82 & $1.86(.82)$ & .76 & $2.49(1.09)$ & .81 \\
\hline Inadequate self & $3.39(1.01)$ & .87 & $3.10(1.01)$ & .86 & $3.56(.98)$ & .88 & $3.11(.98)$ & .86 & $3.73(.95)$ & .87 \\
\hline SWLS & $3.77(1.35)$ & .87 & $3.74(1.37)$ & .88 & $3.79(1.35)$ & .86 & $4.07(1.29)$ & .86 & $3.41(1.34)$ & .87 \\
\hline
\end{tabular}

ASI, Ambivalent Sexism, SWLS Satisfaction with Life Scale 
root mean squared residual (SRMR) (Hu \& Bentler, 1999; McDonald \& Ho, 2002). Next, to compare the Perceived Similarity to Gender Groups Scale scores across gender and sexual orientation, configural, metric, and scalar measurement invariance (MI) were tested on the factorial structure derived from the CFA. Given the sensitivity of $\chi^{2}$ test to sample size, we followed Chen's (2007) guidelines to consider $\Delta \chi^{2}$ tests and $\Delta$ CFI, $\Delta$ RMSEA to inspect changes in model fit between nested models. A difference smaller than 0.010 for $\triangle \mathrm{CFI}$ and 0.015 for $\triangle \mathrm{RMSEA}$ indicated that the additional constraints were tenable and that MI was supported. Once full or partial scalar MI was established, we tested whether latent means were significantly different between groups. One group was chosen as a reference group with its latent means fixed to zero, whereas factor means of the other group were freely estimated (Schwartz et al., 2014). Finally, bivariate correlations among the study scales were run to test validity with the Perceived Similarity to Gender Groups Scales.

\section{Results}

\section{Exploratory Factor Analysis}

An EFA using Geomin as the oblique method of rotation (Muthén \& Muthén, 2012) was conducted to test the dimensionality of the Similarity scale. To evaluate if the hypothesized 2-factor structure was appropriate, we ran two preliminary EFAs, in which we extracted 1 and 2 factors. Then, we compared their fit indexes and examined the interpretability of their factor solution to determine the number of factors to be retained. The 2-factor solution $\chi^{2}(26)=100.812$, $p<0.001$; CFI $=0.910$; RMSEA $=0.126$ [90\% CI: 0.101, $0.113]$, SRMR $=0.042$ showed a better fit than the 1 -factor solution (i.e., $\Delta \chi^{2}(9)=223.07, p<0.001$ ). Although the 2 -factor solution provided a better fit to the data, it was still marginally acceptable. As a next step, we deleted those items showing low primary loadings and/or high cross-loadings, and the 2-factor EFA was repeated. In accordance with the original validation study (Martin et al., 2017), items 5 and 6 (i.e., "look like [girls/boys]") were removed due to their high cross-loadings in the two factors. In addition, items 9 and 10 (i.e., "like to spend time with [girls/boys]") presented low loadings and were therefore removed. The remaining 6 items loaded strongly only onto their respective intended factor (see Table 3) and showed an excellent fit $\chi^{2}(4)=4.482$, $p<0.344$; CFI $=0.999$; RMSEA $=0.026$ [90\% CI: 0.000, $0.118]$, SRMR $=0.014$. The first factor, labeled Similarity to female gender (SFG), taps into individuals' perception of being similar and typical to women and was defined by three items (factor loadings ranged from 0.61 to 0.91 ); the second factor, labeled Similarity to male gender (SMG), taps into individuals' perception of being similar and typical to men (factor loadings ranged from 0.69 to 0.81 ). The factor correlation matrix indicated that SFG and SMG were negatively and significantly correlated at $p \leq 0.01$.

\section{CFA and MI}

Next, to the robustness of the identified 2-factor structure, we conducted a CFA on the validation sample. The 2 -factor structure fitted the data well $\left(\chi^{2}(8)=12.773, p<0.119\right.$; $\mathrm{CFI}=0.996$; $\mathrm{RMSEA}=0.039$ [90\% CI: 0.000, 0.077], SRMR $=0.020$ ). All items showed high standardized factor loadings (range from 0.70 to 0.90 ), and both factors showed good reliability coefficients (Table 3 ). The English and Italian items are presented in Appendix. To compare the scale's score across the groups at the latent level, we tested the scale's comparability across gender and sexual orientation by establishing its MI in a multiple-group analytic framework (Millsap, 2012) (see Supplemental File 1 for model fit comparisons).

Regarding MI across gender, the configural invariance model fits the data very well $\left(\chi^{2}(16)=27.014, p<0.041\right.$; $\mathrm{CFI}=0.988$; $\mathrm{RMSEA}=0.059$ [90\% CI: 0.012, 0.097], SRMR $=0.039$ ). The further constraints of the factor loadings in the metric invariance model showed a worsening in the model fit (i.e., $\Delta \chi^{2}(4)=56.025, p<0.001$; $\Delta \mathrm{CFI}=+0.058)$, thereby attesting the need to let some factor loadings vary between males and females. The factor loadings of items 1 and 2 ("How similar do you feel to [females/males]") and 6 ("How much do you like to do the

Table 3 EFA factor loadings

\begin{tabular}{llll}
\hline & & $\begin{array}{l}\text { Similarity to female } \\
\text { gender } \\
(\text { SFG })\end{array}$ & $\begin{array}{l}\text { Similarity to } \\
\text { male gender } \\
\text { (SMG) }\end{array}$ \\
\hline 1 & How similar do you feel to girls & .80 & \\
3 & How much do you act like girls & .81 & .91 \\
7 & How much do you like to do the same things as girls? & .69 & .76 \\
2 & How similar do you feel to boys & & .62 \\
4 & How much do you act like boys & & \\
8 & How much do you like to do the same things as boys? & & \\
\hline
\end{tabular}


Table 4 Convergent and divergent validity correlations divided for gender

\begin{tabular}{lllllll}
\hline & \multicolumn{2}{l}{ Males } & & & & Females \\
\hline & $(1)$ & $(2)$ & $(3)$ & $(4)$ & $(5)$ & $(6)$ \\
Own-Gender Similarity & - & $-.13^{*}$ & $.14^{* *}$ & $-.13^{*}$ & -.03 & $.17 * *$ \\
Other-Gender Similarity & $-.56^{* *}$ & - & $-14^{* *}$ & .04 & 02 & .01 \\
ASI & $.49 * *$ & $-.39^{* *}$ & - & $-.22^{* *}$ & $-.21^{* *}$ & $.14^{* *}$ \\
Hated Self & $-.24 * *$ & $.20^{* *}$ & -.03 & - & $.69 * *$ & $-.44^{* *}$ \\
Inadequate Self & $-.28^{* *}$ & $.26^{* *}$ & -.07 & $.63^{* *}$ & - & $-.43^{* *}$ \\
SWLS & $.23^{* *}$ & -.11 & .05 & $-.36^{* *}$ & $.49^{* *}$ & - \\
\hline
\end{tabular}

ASI, Ambivalent Sexism; SWLS, Satisfaction with Life Scale

${ }^{*} p<.05 ; * * p<.01$ same things as males") were allowed to vary between groups and models' comparisons gave support to the presence of a partial metric invariance $\left(\Delta \chi^{2}(1)=0.409, p=0.49\right.$; $\Delta \mathrm{CFI}=0.000)$. Next, scalar invariance was tested, and partial invariance was achieved by freeing the intercepts of items 1 ("How similar do you feel to females") and 6 ("How much do you like to do the same things as males") $\left(\Delta \chi^{2}\right.$ $(1)=0.409, p=0.49 ; \Delta \mathrm{CFI}=0.000$ ).

Then, we compared the scales across gender groups: We found that male adults showed significantly lower latent levels of SFG and significantly higher levels of SMG compared to female adults $(z=-8.81, p<0.001 ; z=1.47, p<0.001$, respectively), showing that males perceived themselves as more typical to the male gender and less typical to female gender compared to females. Regarding sexual orientation, the configural invariance model fits the data very well $\left(\chi^{2}\right.$ $(16)=31.626, p<0.011 ; \mathrm{CFI}=0.987 ; \mathrm{RMSEA}=0.071[90 \%$ CI: 0.033, 0.107], SRMR $=0.031)$. Full metric and scalar invariance were also confirmed $\left(\Delta \chi^{2}(4)=0.409, p=0.98\right.$; $\Delta \mathrm{CFI}=0.003$, and $\Delta \chi^{2}(4)=6.188, p=0.18 ; \Delta \mathrm{CFI}=0.004$, respectively) supporting the comparability of the Perceived Similarity to Gender Groups Scale between heterosexual people and LGB + participants. Latent mean comparisons showed that in the present sample, LGB + individuals showed significantly lower latent levels of SMG than heterosexual individuals $(z=-2.50, p<0.05)$, showing that LGB + individuals perceived themselves as less typical to the male gender compared to heterosexual individuals. No significant latent mean differences were found on SFG across sexual orientation.

\section{Convergent and Divergent Validity}

To test for validity, in line with the scale's conceptualization (i.e., Martin et al., 2017a), scores of the two SMG and SFG factors were re-calculated to reflect the participants' own- and other-gender similarity (i.e., SMG for men and SFG for women). The two factors were then labeled owngender similarity to reflect the perception of being similar or typical to one's own-gender and other-gender similarity reflecting the perception of being similar or typical to the other gender (see Table 2 for reliability and descriptives). Bivariate correlations were then performed to examine the convergent validity of the Perceived Similarity to Gender Groups Scale (i.e., own- and other-gender similarity) with the Ambivalent Sexism Inventory and the Self-Criticizing/ Attacking Scale. Divergent validity was examined through bivariate correlations between the two typicality factors and the Life Satisfaction Scale. Correlations across gender and sexual orientation are presented in Tables 4 and 5.

The own-gender similarity factor was positively correlated to the ASI score for both males and females and the heterosexual individuals, while no significant association was found for LGB + people. The own-gender similarity
Table 5 Convergent and divergent validity correlations divided for sexual orientation

\begin{tabular}{llllllc}
\hline & Heterosexual & & & & & LGB + \\
\hline & $(1)$ & $(2)$ & $(3)$ & $(4)$ & $(5)$ & $(6)$ \\
Own-Gender Similarity (1) & - & $.09^{*}$ & .05 & -.00 & .04 & .04 \\
Other-Gender Similarity (2) & $-.36^{* *}$ & - & -.07 & .00 & .03 & .05 \\
ASI (3) & $.30^{* *}$ & $-.33^{* *}$ & - & $-.15^{* *}$ & $-.15^{* *}$ & -.06 \\
Hated Self (4) & $-.16^{* *}$ & $.08^{* *}$ & -.00 & - & $.68^{* *}$ & $-.36^{* *}$ \\
Inadequate Self (5) & -.10 & $.14^{* *}$ & -.04 & $.61^{* *}$ & - & $-.36^{* *}$ \\
SWLS (6) & $.19^{* *}$ & -.00 & .04 & $-.35^{* *}$ & $.38^{* *}$ & - \\
\hline
\end{tabular}

ASI, Ambivalent Sexism; SWLS, Satisfaction with Life Scale ${ }^{*} p<.05 ; * * p<.01$ 
factor was also negatively associated with Hated Self for both male and female adults, while this association was significant only for heterosexual individuals. Furthermore, one negative and significant association was found between the own-gender similarity factor and the Inadequate Self subscale, but only for males. The othergender similarity factor was negatively correlated to the ASI score for both males and females and the heterosexual individuals, while no significant association was found for the LGB + participants. The other-gender similarity factor was also positively associated with Hated Self only for male adults, and positive associations were found between the other-gender similarity factor and the Inadequate Self only for males and heterosexual individuals.

Regarding divergent validity, the bivariate correlations of the own-gender similarity factor were positively correlated to the SWLS score for both males and females and the heterosexual individuals, while no significant association was found for the LGB + participants. To note, regarding the other-gender similarity factor, no significant associations were found with SWLS for either male adults or female adults and heterosexual and LGB + individuals.

\section{Discussion Study 1}

The purpose of the present study was to validate a gendertypicality measure in a sample of young Italian adults who varied in gender and sexual orientation. Young adulthood is a critical life stage for defining and further refining one's identity, and for gender identity, this development is likely related to changing development goals and the social expectancies related to this age (Arnett, 2000; Barret $\&$ White, 2002; Marcell et al., 2011). In line with previous studies in childhood and young adulthood (Andrews et al., 2019; Martin et al., 2017a), results of the exploratory factor analysis revealed that the scale is composed of two different factors: (1) similarity to male gender, reflecting the perception of being similar or typical to males, and (2) similarity to female gender, reflecting the perception of being similar or typical to females. Furthermore, the factors are low to moderately negatively related. These results support the dual-identity approach by providing additional empirical support for the structural distinction between one's own-gender typicality and other-gender typicality (Martin et al., 2017a, b).

The CFA results revealed that the two-factor structure of the Perceived Similarity to Gender Groups Scale was the best fit for the data: The comparability of the scale across gender and sexual orientation was supported by configural, metric, and scalar measurement invariance (MI). Correlations with the ASI, Self-Criticizing/Attacking Scale, and the SWLS demonstrated convergent and divergent validity. Interestingly, the factorial structure for similarity partially differed from what was found in children (Martin et al., 2017a) and in US adults (Andrews et al., 2019).

Notably, the items which assess similarity in appearance (i.e., items 5 and 6 "look like [females/males]") and that assess social preferences (i.e., "like to spend time with [females/males]") did not load strongly only into their respective intended factor. While the first result was also found in Andrew and colleagues' (2019) study, the similarity in hanging out with someone was new. These results could be interpreted in light of the cognitivedevelopmental perspective, highlighting that increased cognitive maturity and complexity in adults could allow them to think about themselves and their gender typicality more flexibly (Andrews et al., 2019; Endendijk et al., 2019; Erikson, 1968; Kohlberg, 1966). Moreover, gender flexibility both in appearance and hanging out with someone could depict a sign of better adjustment and changing social interests or social expectancies. Adults may have more flexibility in choices of people with whom they spend time as compared to children, given peer group pressures in childhood.

\section{Study 2}

\section{Method}

\section{Participants and Procedures}

The participants' recruitment and procedure were the same as in the first study. A total of $1126(76.1 \%$ females) Italian individuals participated in the study. The sample involved heterosexual people $(n=319 ; 64.3 \%$ females), heteroflexible people (people who defined themselves as "mostly heterosexual"; $n=285 ; 85.6 \%$ females), and LGB + people ( $n=522 ; 78.2 \%$ females), including bisexual people $(n=239)$, gay men $(n=85)$, lesbian women $(n=140)$, and other sexual orientations (i.e., same-gender-loving, men who have sex with men, women who have sex with women, bi-curious, and questioning; $n=58 ; 86 \%$ females). Respondents' biological sex was investigated through a close-ended question in which they could depict themselves as "male," "female," or "intersex." Two participants $(0.2 \%)$ defined themselves as intersex: We did not include them in the final sample. Participants' ages ranging from 18 to 32 years $(M=24.3, \mathrm{SD}=3.51)$. The ANOVA conducted on age showed that in the present sample, heteroflexible people were older than both the heterosexual and LGB + people $(F(1,1123)=17.797, p<0.001)$. Age, education, 
Table 6 Sample demographics

\begin{tabular}{|c|c|c|c|c|c|c|c|c|}
\hline & \multicolumn{2}{|c|}{$\begin{array}{l}\text { Total sample } \\
N=1126 \\
(100 \%)\end{array}$} & \multicolumn{2}{|c|}{$\begin{array}{l}\text { Heterosexual } \\
N=319 \\
(28.3 \%)\end{array}$} & \multicolumn{2}{|c|}{$\begin{array}{l}\text { Heteroflexible } \\
N=285 \\
(25.3 \%)\end{array}$} & \multicolumn{2}{|c|}{$\begin{array}{l}\mathrm{LGB}+ \\
N=522 \\
(46.4 \%)\end{array}$} \\
\hline & $N$ & $\%$ & $N$ & $\%$ & $N$ & $\%$ & $N$ & $\%$ \\
\hline \multicolumn{9}{|l|}{ Education } \\
\hline Middle school diploma & 54 & 4.8 & 8 & 2.5 & 9 & 3.2 & 37 & 7.1 \\
\hline High school diploma & 517 & 45.9 & 141 & 44.2 & 103 & 36.1 & 273 & 52.3 \\
\hline Bachelor's degree & 253 & 22.5 & 81 & 25.4 & 79 & 27.7 & 93 & 17.8 \\
\hline Master's degree & 253 & 22.4 & 75 & 23.5 & 78 & 27.4 & 100 & 19.2 \\
\hline Postgraduate level & 49 & 4.4 & 14 & 4.4 & 16 & 5.6 & 19 & 3.6 \\
\hline \multicolumn{9}{|l|}{ SES } \\
\hline Extremely low & 10 & 0.9 & 2 & 0.6 & 3 & 1.1 & 5 & 1.0 \\
\hline Low & 186 & 16.5 & 34 & 10.7 & 59 & 20.7 & 93 & 17.8 \\
\hline Average & 835 & 74.2 & 253 & 79.3 & 203 & 71.2 & 379 & 72.6 \\
\hline High & 94 & 8.3 & 29 & 9.1 & 20 & 7.0 & 45 & 8.6 \\
\hline Extremely high & 1 & 0.1 & 1 & 0.3 & 0 & 0 & 0 & 0 \\
\hline \multicolumn{9}{|l|}{ Relationship status } \\
\hline Single & 504 & 44.8 & 112 & 35.1 & 112 & 39.3 & 280 & 53.6 \\
\hline Engaged (not cohabiting) & 381 & 33.8 & 140 & 43.9 & 81 & 28.4 & 160 & 30.7 \\
\hline Cohabiting & 176 & 15.6 & 51 & 16.0 & 63 & 22.1 & 62 & 11.8 \\
\hline Civil union & 6 & 0.6 & 0 & 0 & 2 & 0.7 & 4 & 0.8 \\
\hline Married & 34 & 3.0 & 14 & 4.4 & 16 & 5.6 & 4 & 0.8 \\
\hline Other & 25 & 2.2 & 2 & 0.6 & 11 & 3.9 & 12 & 2.3 \\
\hline
\end{tabular}

SES, and relationship status distributions are reported in Table 6.

\section{Measures}

\section{Perceived Similarity to Gender Groups Scale}

The Perceived Similarity to Gender Groups Scale was adopted from study 1 . Scores were averaged to create the two subscales identified in study 1 according to participants' gender. Both own-gender similarity and other-gender similarity showed good reliability values (see Supplemental File $2 a, b$, and $c)$.

\section{Data Analytic Plan}

To answer our research questions, in line with previous studies (e.g., Andrews et al., 2019; Endendijk et al., 2019; Martin et al., 2017a), a non-hierarchical $k$-mean clustering method was implemented to identify gender-identity typologies among participants. Gender-identity typologies were derived from participants' responses to the Perceived Similarity to Gender Groups Scale (Martin et al., 2017a). Considering that our sample was slightly homogeneous in terms of socioeconomical characteristics, before implementing the clustering analysis, we converted our grouping variables to $z$-scores using the same cluster centers (e.g., Akse et al., 2004; Scholte et al., 2005). We set the number of clusters to four, according to previous works that identified and replicated a four-type solution (e.g., Andrews et al., 2019; Martin et al., 2017a). Thus, to test whether the identified typologies differed on their gender identity, a univariate analysis of variance with subsequent Tukey post hoc test with $p<0.001$ was performed using the standardized ownand other-gender similarity scores of our participants (e.g., Akes et al., 2004; Endendijk et al., 2019).

In addition, we investigated the prevalence and distribution of the identified typologies in our sample: We performed contingency table tests, a chi-square test of association, and considered the adjusted standardized residuals, referring to the distribution of gender and sexual orientation in the identified typologies solution. Descriptive statistics for all study variables, including observed means, standard deviations, and correlations, are presented for the total sample (Supplemental File 2a) and differentiated for gender (Supplemental File 2b) and sexual orientation (Supplemental File 2c).

\section{Results}

\section{Gender-Identity Typologies}

We identified four different types based on participants ownand other-gender similarity, as follows: (1) an own-gender 
profile ( $n=376 ; 33 \%$ of the sample), characterized by high own-gender similarity, and low other-gender similarity; (2) an other-gender profile $(n=402 ; 36 \%$ of the sample, the most prevalent profile), characterized by high other-gender similarity, together with low own-gender similarity; (3) a both-gender profile ( $n=185 ; 16 \%$ of the sample), characterized by high levels of both own- and other-gender similarity; and (4) a low-gender profile $(n=163 ; 15 \%$ of the sample, the less prevalent profile), characterized by lowest levels of both own- and other-gender similarity. Figure 1 shows the graphical representation of the four-typologies solution (z-scores).

The univariate analysis of variance attested that each typology significantly differed from other types in their peculiar characteristics. More specifically, as regards the own-gender similarity $(F(3,1122)=740.03 ; p<0.0001$; $\eta^{2}=0.66$; obs. $\mathrm{pwr}=1.000$ ), the low-gender profile showed the significantly lowest levels of own-gender similarity (mean $=1.43$ ), followed by the other-gender profile (mean $=1.80$ ). According to their characteristics, the bothgender and the own-gender profiles showed the highest levels of own-gender similarity (respectively, mean 2.93 and 3.01). Similarly, considering profiles' levels of other-gender similarity $\left(F(3,1122)=656.55 ; p<0.0001 ; \eta^{2}=0.64\right.$; obs. $\mathrm{pwr}=1.000$ ), the low-gender and the own-gender profiles showed the lowest levels of other-gender similarity (respectively, mean 0.98 and 1.02). The other-gender profile showed medium-to-high levels of other-gender similarity (mean $=2.10$ ), whereas the profile that significantly showed the highest level of this dimension was the both-gender profile (mean $=2.39$ ). Overall, these results confirmed the identification of four different gender-identity typologies. Each of these typologies was defined by specific characteristics in terms of how their members perceived themselves as similar or different from people of their own gender.

Regarding the distribution and the prevalence of the four typologies, we found that the most prevalent profile in our sample was the other-gender group (36\% of the total sample), followed by the own-gender group (33\% of the total sample). The both-gender (16\%) and the low-gender (15\%) groups represented a small percentage of the total sample. The highest prevalence of the other-gender profile could be interpreted in light of the high prevalence of LGB + participants ( $46 \%$ of the total sample).

To deeply investigate these trends, we examined the distribution and the prevalence of our identified typologies using a contingency table, analyzing the chi-square test of association significance and the adjusted standardized residuals. This procedure indicated that considering the gender of our sample, the both-gender and the own-gender groups significantly differed in their distribution $\left(\chi^{2}(3\right.$, $1122)=17.108 ; p=0.001)$. More specifically, in the bothgender group, there were significantly more females than males (adjRes $=2.7 ; 18 \%$ of females and the $11 \%$ of males), and in the own-gender group, there were significantly more males than females (adjRes $=3.7 ; 43 \%$ of males and the $30 \%$ of females).

Regarding sexual orientation, all the identified typologies - except the both-gender group - significantly differed in their distribution $\left(\chi^{2}(6,1122)=86.143\right.$; $p<0.001)$. In particular, the own-gender group was significantly more represented by the heterosexual participants than the expected $(\operatorname{adjRes}=8.9 ; 53 \%$ of the
Fig. 1 Graphical representation of four different gender-identity typologies

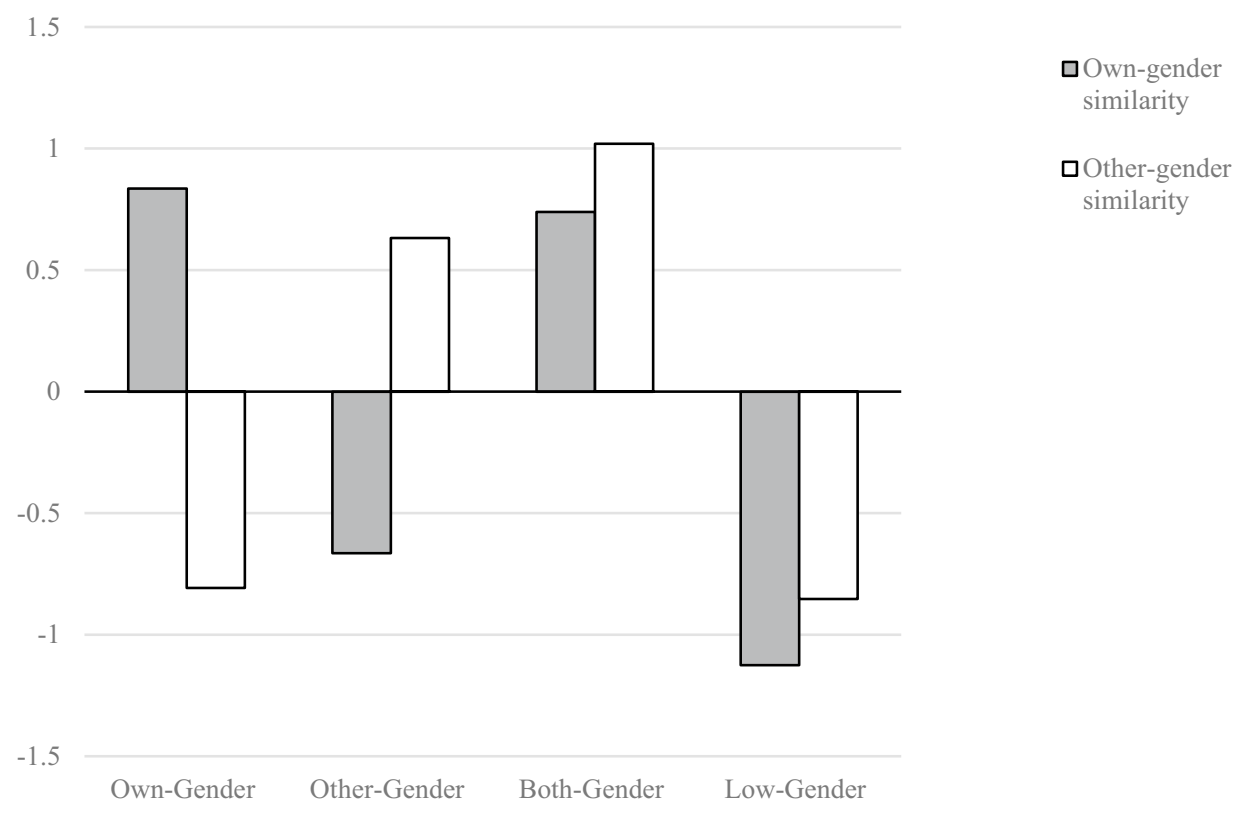

Notes: The graphical representation considered the standardized z-values of gender similarity to represent more clearly the specificity of each profile 
heterosexual people), and significantly less represented by the LGB + and heteroflexible people than the expected (respectively, adjRes -5.6 and $-2.8 ; 25 \%$ of heteroflexible participants and $27 \%$ of LGB +). Regarding the other-gender group, results attested that there were significantly fewer heterosexual individuals than the expected $(\operatorname{adjRes}=-6.5$; the $21 \%$ of heterosexual people) and more LGB + participants than the expected $(\operatorname{adjRes}=4.6$; the $43 \%$ of LGB +). At least, in the low-gender group, we found that this profile was significantly less represented by heterosexual participants than the expected $(\operatorname{adjRes}=-2.1 ; 11 \%$ of heterosexual people $)$.

\section{Discussion Study 2}

In line with previous studies investigating gender typicality through a dual-identity approach, the present study aims to recognize four gender-identity typologies based on individual differences in combining own-gender and other-gender similarity. Results from cluster analysis reported similar groups of gender-identity typologies founded in previous studies: own-gender similarity, other-gender similarity, both-gender similarity, and lastly, low-gender similarity (Andrews et al., 2019; Endendijk et al., 2019; Martin et al., 2017a). Interestingly, the percentage of participants in typicality cluster differs from children (Martin et al., 2017a) and other adults' studies (Andrews et al., 2019; Endendijk et al., 2019). Indeed, we found that the most widespread profile in our sample was the other-gender group (36\% of the total sample), followed by the own-gender group (33\% of the total sample), both-gender group (16\% of the total sample), and low-gender group (15\% of the total sample). The higher numbers of young adults who describe themselves as more gender similar to other gender could be explained in several ways. First, this may be due to the increased cognitive maturity that allows adults to be more flexible in their perception of gender roles as compared to children (Andrews et al., 2019; Barret \& White, 2002; Kohlberg, 1966; Marcell et al., 2011). Second, the higher prevalence of other gender similar in our sample could be partly explained considering the distribution of the sexual orientation in our sample ( $46 \%$ of the total sample was composed of LGB + people). This result is in line with previous studies highlighting that LGB + people described themselves as more gender atypical than typical (Green et al., 2018).

Another aim of the present study was to describe the distributions of different gender-identity typologies depending on gender and sexual orientation. In line with previous studies, males described themselves as more gender similar to their own gender than females, confirming our first hypothesis. This result could be understood in light of social pressure to conform to gender norms, which is higher for male children/ adolescents (Blakemore, 2003; Bukowski et al., 2017; Perry et al., 2019; Ueno \& McWilliams, 2010) and for male adults than females counterparts (Andrews et al., 2019; Dinella et al., 2014). Moreover, data showed that females are more represented in the both-gender similar group, while males are more represented in the own-gender similar group. This result partially confirmed our third hypothesis in which we expected that females would describe themselves as more flexible in their gender typicality than males. Females were more highly represented in the both-gender similar group, but we did not find evidence that they feel more similar to the other-gender peer group than males. Given that the both-gender similar typology has been linked to androgyny (Martin et al., 2017b; Pauletti et al., 2017), their strong representation in this group suggests that they hold more flexible attitudes toward ownand other-gender typicality (Martin \& Fabes, 2001; Martin et al., 2017a; Perry et al., 2019; Ruble et al., 2007).

Regarding sexual orientation, our results confirmed our fourth hypothesis showing that LGB + individuals were less represented in the own-gender similar profile compared to heterosexual people. Specifically, this result is in line with previous studies highlighting that LGB + people tend to feel more atypical than typical to their own gender (Dunne et al., 2000; Green et al., 2018; Hässler et al., 2021; Lippa, 2002, 2008; Salvati et al., 2018). Generally, results illustrated the value of utilizing this view of gender typicality which considers own- and other-gender similarity as independent and informative dimensions of gender typicality in young adulthood samples.

\section{Limitation of the Study and Future Directions}

Much of the research on gender typicality focuses on children, adolescents, and adults who lived in WEIRD (Western Educated Industrial Rich and Democratic) countries and particularly in the United States and North Europe (Andrews et al., 2019; Egan \& Perry, 2001; Endendijk et al., 2019; Martin et al., 2017a). We recognize that what is typical for males and females differs across cultures and intergroup contexts, so cross-cultural research is needed to better understand the definition and development of gender typicality and the different implications of its attribution across cultures. It would be a worthy goal of future research to verify the scale's validity and explore its usefulness among varying age groups in non-western countries.

The study has some limitations. First, we used a convenience sample, and future studies using other sampling methods and other samples are necessary. Second, the effect of social desirability must be controlled when data are collected with self-report questionnaires. Third, we did not consider the relevance of the variables associated with gender typicality, such as age, socioeconomic status, educational level, 
ethnicity, and religiosity. Fourth, we did not investigate the effect of the coronavirus disease (COVID-19) pandemic on the self-perception of gender typicality: Future research could deeply investigate this effect using retrospective approaches. Finally, another limitation concerns the composition of participants' gender identities: Future research may investigate the development and definition of gender typicality, including transgender people and non-binary people, to understand better the complexity of gender typicality and be more representative of the different nuances of gender identity. Ideally, the Perceived Similarity to Gender Groups Scale would also be used in longitudinal studies, which allows a closer examination of the trajectories of gender typicality during different life stages, like adolescence and late adulthood, to improve understanding of changes in typicality over different periods of life.

In sum, the present study highlights the relevance of studying gender typicality in young adulthood and of doing so using a broad sample of participants who vary in gender and sexual orientation. Consistent with the early views about gender involving multiple dimensions and akin to today's views of the importance of understanding intersecting identities, the dual-identity approach better represents the complexity of gender identity and considers the experiences of those who feel similar to both genders or neither (Bem, 1981; Shields, 2008). This conceptualization has important clinical and social implications: It underlines the relevance of approaching gender typicality and gender identity in a more flexible way, moving beyond the gender binary (Martin et al., 2017b). In line with this, it is evident that many adults perceived themselves to be more than simply fitting into male and female categories and instead described themselves as having a more complex, singular, and flexible experience of gender identity (Andrews et al., 2019).

\section{Policy Implications}

The use of the dual-identity approach has significant social and clinical implications as it represents a more flexible and representative model of the complexity of this construct. Being open to individuals expressing a more flexible perception of gender typicality allows one to recognize and understand those who do not identify themselves within a binary vision of gender and helps health and social care professionals increase the quality of care for vulnerable and minority groups (Baiocco et al., 2021). Moreover, this flexible perspective about gender could also have important implications in the school context and in the educational system, promoting more inclusive and safe spaces for all gender identities. Indeed, approaching gender typicality in a plural way at school could allow to recognize different gender identities and expressions, build a more inclusive society, and support youth's well-being. Thus, more significant efforts are needed to consider gender typicality and its relationship with well-being and social competence, particularly for LGBT + people.

A dual-identity approach to gender typicality helps to redefine a stereotyped vision of gender, opening up toward a plural and inclusive society. We believe that too little attention has been focused on gender typicality during adulthood: This is a relevant topic that was often ignored, despite its significant potential to promote well-being and social competence. We hope this article will help the scientific community promote studies evaluating gender typicality across sexual orientation and gender identity dimensions, especially in countries like Italy, characterized by high levels of socialsexual stigma and negative beliefs regarding the gender people who feel or express themselves as being less typical of their own gender.

\section{Appendix Revised version of the Perceived Similarity to Gender Groups Scale: English and Italian version}

\begin{tabular}{|c|c|c|c|}
\hline & English version & & Italian version \\
\hline (1) & $\begin{array}{l}\text { How similar do you feel to } \\
\text { girls? }\end{array}$ & (1) & $\begin{array}{l}\text { Quanto ti senti simile alle } \\
\text { donne? }\end{array}$ \\
\hline (2) & $\begin{array}{l}\text { How similar do you feel to } \\
\text { boys? }\end{array}$ & (2) & $\begin{array}{l}\text { Quanto ti senti simile agli } \\
\text { uomini? }\end{array}$ \\
\hline (3) & $\begin{array}{l}\text { How much do you act like } \\
\text { girls? }\end{array}$ & (3) & $\begin{array}{l}\text { Quanto ti comporti come le } \\
\text { donne? }\end{array}$ \\
\hline (4) & $\begin{array}{l}\text { How much do you act like } \\
\text { boys? }\end{array}$ & (4) & $\begin{array}{l}\text { Quanto ti comporti come gli } \\
\text { uomini? }\end{array}$ \\
\hline (5) & $\begin{array}{l}\text { How much do you like to } \\
\text { do the same things as } \\
\text { girls? }\end{array}$ & (5) & $\begin{array}{l}\text { Quanto ti piace fare le stesse } \\
\text { cosec he generalmente } \\
\text { fanno le donne? }\end{array}$ \\
\hline (6) & $\begin{array}{l}\text { How much do you like to } \\
\text { do the same things as } \\
\text { boys? }\end{array}$ & (6) & $\begin{array}{l}\text { Quanto ti piace fare le stesse } \\
\text { cose che generalmente } \\
\text { fanno gli uomini? }\end{array}$ \\
\hline
\end{tabular}

Responses ranged from 0 (not similar at all) to 4 (very similar). Subscale scores are computed by averaging subscale item ratings: similarity to female gender $(1,3,5)$ and similarity to male gender $(2,4,6)$.

Supplementary Information The online version contains supplementary material available at https://doi.org/10.1007/s13178-021-00631-5.

Author Contribution Roberto Baiocco and Concetta Pastorelli contributed to the study conception and design. Material preparation and data collection: Chiara Antoniucci and Jessica Pistella. Methodology, formal 
analyses, and investigation: Emanuele Basili and Ainzara Favini. Writing - original draft preparation: Roberto Baiocco, Chiara Antoniucci, Emanuele Basili, and Jessica Pistella. Writing — review and editing: Roberto Baiocco, Carol Martin, Concetta Pastorelli, Ainzara Favini, and Jessica Pistella. Supervision: Roberto Baiocco, Carol Martin, and Concetta Pastorelli. All authors read and approved the final manuscript.

Funding Open access funding provided by Università degli Studi di Roma La Sapienzawithin the CRUI-CARE Agreement.

Data Availability The data are available upon request to the authors.

\section{Declarations}

Ethical Approval All procedures performed in studies involving human participants were in accordance with the ethical standards of the institutional and/or national research committee and with the 1964 Helsinki Declaration and its later amendments or comparable ethical standards. Approval was granted by the Ethic Committee of Sapienza University of Rome.

Informed Consent Informed consent was obtained from all individual participants included in the study.

Conflict of Interest The authors declare no competing interests.

Open Access This article is licensed under a Creative Commons Attribution 4.0 International License, which permits use, sharing, adaptation, distribution and reproduction in any medium or format, as long as you give appropriate credit to the original author(s) and the source, provide a link to the Creative Commons licence, and indicate if changes were made. The images or other third party material in this article are included in the article's Creative Commons licence, unless indicated otherwise in a credit line to the material. If material is not included in the article's Creative Commons licence and your intended use is not permitted by statutory regulation or exceeds the permitted use, you will need to obtain permission directly from the copyright holder. To view a copy of this licence, visit http://creativecommons.org/licenses/by/4.0/.

\section{References}

Akse, J., Hale, W. W., Engels, R. C., Raaijmakers, Q. A., \& Meeus, W. H. (2004). Personality, perceived parental rejection and problem behavior in adolescence. Social Psychiatry and Psychiatric Epidemiology, 39(12), 980-988. https://doi.org/10.1007/ s00127-004-0834-5

Andrews, N. C. Z., Martin, C. L., Cook, R. E., Field, R. D., \& England, D. E. (2019). Exploring dual gender typicality among young adults in the United States. International Journal of Behavioral Development, 43(4), 314-321. https://doi.org/10.1177/0165025418811125

Arnett, J. J. (2000). Emerging adulthood: A theory of development from the late teens through the twenties. American Psychologist, 55(5), 469-480. https://doi.org/10.1037/0003-066X.55.5.469

Bailey, J. M., \& Zucker, K. J. (1995). Childhood sex-typed behavior and sexual orientation: A conceptual analysis and quantitative review. Developmental Psychology, 31(1), 43-55. https://doi.org/ 10.1037/0012-1649.31.1.43

Baiocco, R., Pezzella, A., Pistella, J., Kouta, C., Rousou, E., \& Papadopoulos, I. (2021). LGBT+ training needs for health and social care professionals: A cross-cultural comparison among seven European countries. Advance online publication. https:// doi.org/10.1007/s13178-020-00521-2
Barrett, A. E., \& White, H. R. (2002). Trajectories of gender role orientations in adolescence and early adulthood: A prospective study of the mental health effects of masculinity and femininity. Journal of Health and Social Behavior, 43(4), 451-468. https://doi.org/ $10.2307 / 3090237$

Bem, S. L. (1981). Gender schema theory: A cognitive account of sex typing. Psychological Review, 88(4), 354-364. https://doi.org/10. 1037/0033-295X.88.4.354

Bem, S. L. (1985). Androgyny and gender schema theory: A conceptual and empirical integration. In T. B. Sonderegger (Ed.), Nebraska Symposium on Motivation 1984: Psychology and gender (pp. 179-226). University of Nebraska Press.

Bjornsdottir, T. R., \& Rule, N. O. (2020). Emotion and gender typicality cue sexual orientation differently in women and men. Archives of Sexual Behavior, 49, 2547-2560. https://doi.org/10.1007/ s10508-020-01700-3

Blakemore, J. E. O. (2003). Children's beliefs about violating gender norms: Boys shouldn't look like girls, and girls shouldn't act like boys. Sex Roles, 48(9), 411-419. https://doi.org/10.1023/A: 1023574427720

Braun, S. S., \& Davidson, A. J. (2017). Gender (non) conformity in middle childhood: A mixed methods approach to understanding gender-typed behavior, friendship, and peer preference. Sex Roles, 77(1), 16-29. https://doi.org/10.1007/s11199-016-0693-z

Bukowski, W. M., Castellanos, M., Commisso, M., Persram, R., \& Lopez, L. S. (2019). Contextual variations in children's perceptions of their peers as gender typical. International Journal of Behavioral Development, 43(4), 309-313. https://doi.org/10.1177/ 0165025419846427

Bukowski, W. M., Panarello, B., \& Santo, J. B. (2017). Androgyny in liking and in being liked are antecedent to well-being in preadolescent boys and girls. Sex Roles, 76(11), 719-730. https://doi. org/10.1007/s11199-016-0638-6

Carver, P. R., Yunger, J. L., \& Perry, D. G. (2003). Gender identity and adjustment in middle childhood. Sex Roles, 49(3), 95-109. https:// doi.org/10.1023/A:1024423012063

Chen, F. F. (2007). Sensitivity of goodness of fit indexes to lack of measurement invariance. Structural Equation Modeling: A Multidisciplinary Journal, 14(3), 464-504. https://doi.org/10.1080/ 10705510701301834

Constantinople, A. (1973). Masculinity-femininity: An exception to a famous dictum? Psychological Bulletin, 80(5), 389-407. https:// doi.org/10.1177/0959-353505057611

Cowie, L. J., Greaves, L. M., \& Sibley, C. G. (2019). Sexuality and sexism: Differences in ambivalent sexism across gender and sexual identity. Personality and Individual Differences, 148, 85-89. https://doi.org/10.1016/j.paid.2019.05.023

DiDonato, M. D., Martin, C. L., Hessler, E. E., Amazeen, P. G., Hanish, L. D., \& Fabes, R. A. (2012). Gender consistency and flexibility: Using dynamics to understand the relationship between gender and adjustment. Nonlinear Dynamics, Psychology, and Life Sciences, 16(2), 159-184.

DiDonato, M. D., \& Berenbaum, S. A. (2013). Predictors and consequences of gender typicality: The mediating role of communality. Archives of Sexual Behavior, 42(3), 429-436. https://doi.org/10. 1007/s10508-012-9955-1

Diener, E. D., Emmons, R. A., Larsen, R. J., \& Griffin, S. (1985). The satisfaction with life scale. Journal of Personality Assessment, 49(1), 71-75. https://doi.org/10.1207/s15327752jpa4901_13

Dinella, L. M., Fulcher, M., \& Weisgram, E. S. (2014). Sex-typed personality traits and gender identity as predictors of young adults' career interests. Archives of Sexual Behavior, 43(3), 493-504. https://doi.org/10.1007/s10508-013-0234-6

Doescher, S. M., \& Sugawara, A. I. (1990). Sex role flexibility and prosocial behavior among preschool children. Sex Roles, 22(1-2), 111-123. 
Dunne, M. P., Bailey, J. M., Kirk, K. M., \& Martin, N. G. (2000). The subtlety of sex-atypicality. Archives of Sexual Behavior, 29(6), 549-565. https://doi.org/10.1023/A:1002002420159

Egan, S. K., \& Perry, D. G. (2001). Gender identity: A multidimensional analysis with implications for psychosocial adjustment. Developmental Psychology, 37(4), 451-463. https://doi.org/10. 1037/0012-1649.37.4.451

Endendijk, J. J., Andrews, N. C. Z., England, D. E., \& Martin, C. L. (2019). Gender-identity typologies are related to gender-typing, friendships, and social-emotional adjustment in Dutch emerging adults. International Journal of Behavioral Development, 43(4), 322-333. https://doi.org/10.1177/0165025418820686

Erikson, E. H. (1968). Identity: Youth and crisis. Norton. https://doi. org/10.1126/science.161.3838.257

Kim, E. S., \& Yoon, M. (2011). Testing measurement invariance: A comparison of multiple-group categorical CFA and IRT. Structural Equation Modeling, 18(2), 212-228. https://doi.org/10. 1080/10705511.2011.557337

Gilbert, P., Clarke, M., Hempel, S., Miles, J. N., \& Irons, C. (2004). Criticizing and reassuring oneself: An exploration of forms, styles and reasons in female students. British Journal of Clinical Psychology, 43(1), 31-50. https://doi.org/10.1348/014466504772812959

Glick, P., \& Fiske, S. T. (1996). The ambivalent sexism inventory: Differentiating hostile and benevolent sexism. Journal of Personality and Social Psychology, 70(3), 491-512. https://doi.org/ 10.1037/0022-3514.70.3.491

Green, L., Rimes, K. A., \& Rahman, Q. (2018). Beliefs about others' perceptions - gender typicality: Scale development and relationships to gender nonconformity, sexual orientation, and wellbeing. The Journal of Sex Research, 55(7), 837-849. https:// doi.org/10.1080/00224499.2017.1384785

Hässler, T., Ullrich, J., Sebben, S., Shnabel, N., Bernardino, M., ... \& Pistella, J. (2021). Needs satisfaction in intergroup contact: A multi-national study of pathways toward social change. Journal of Personality and Social Psychology. Advance online publication. https://doi.org/10.1037/pspi0000365

Hu, L. T., \& Bentler, P. M. (1999). Cutoff criteria for fit indexes in covariance structure analysis: Conventional criteria versus new alternatives. Structural Equation Modeling: A Multidisciplinary Journal, 6(1), 1-55. https://doi.org/10.1080/10705519909540118

Jewell, J. A., \& Brown, C. S. (2014). Relations among gender typicality, peer relations, and mental health during early adolescence. Social Development, 23(1), 137-156. https://doi.org/10.1111/ sode. 12042

Kohlberg, L. (1966). A cognitive-developmental analysis of children's sex-role concepts and attitudes. In E. E. Maccoby (Ed.), The development of sex differences (pp. 82-173). Stanford University Press.

Leaper, C., \& Van, S. R. (2008). Masculinity ideology, covert sexism, and perceived gender typicality in relation to young men's academic motivation and choices in college. Psychology of Men \& Masculinity, 9(3), 139-153. https://doi.org/10.1037/1524-9220.9.3.139

Leaper, C., Farkas, T., \& Brown, C. S. (2012). Adolescent girls' experiences and gender-related beliefs in relation to their motivation in math/science and english. Journal of Youth and Adolescence, 41, 268-282. https://doi.org/10.1007/s10964-011-9693-z

Lee, E. A. E., \& Troop-Gordon, W. (2011). Peer processes and gender role development: Changes in gender atypicality related to negative peer treatment and children's friendships. Sex Roles, 64(1-2), 90-102. https://doi.org/10.1007/s11199-010-9883-2

Lefkowitz, E. S., \& Zeldow, P. B. (2006). Masculinity and femininity predict optimal mental health: A belated test of the androgyny hypothesis. Journal of Personality Assessment, 87(1), 95-101. https://doi.org/10.1207/s15327752jpa8701_08

Lippa, R. A. (2002). Gender-related traits of heterosexual and homosexual men and women. Archives of Sexual Behavior, 31(1), 83-98. https://doi.org/10.1023/A:1014035302843
Lippa, R. A. (2008). The relation between childhood gender nonconformity and adult masculinity-femininity and anxiety in heterosexual and homosexual men and women. Sex Roles, 59(910), 684-693. https://doi.org/10.1007/s11199-008-9476-5

Marcell, A. V., Eftim, S. E., Sonenstein, F. L., \& Pleck, J. H. (2011). Associations of family and peer experiences with masculinity attitude trajectories at the individual and group level in adolescent and young adult males. Men and Masculinities, 14(5), 565-587. https://doi.org/10.1177/1097184X11409363

Martin, C. L., \& Fabes, R. A. (2001). The stability and consequences of young children's same-sex peer interactions. Developmental Psychology, 37(3), 431-446. https://doi.org/10.1037/0012-1649. 37.3.431

Martin, C. L., Andrews, N. C. Z., England, D. E., Zosuls, K., \& Ruble, D. N. (2017a). A dual identity approach for conceptualizing and measuring children's gender identity. Child Development, 88(1), 167-182. https://doi.org/10.1111/cdev.12568

Martin, C. L., Cook, R., \& Andrews, N. C. Z. (2017b). Reviving androgyny: A modern day perspective on flexibility of gender identity and behavior. Sex Roles, 76, 592-603. https://doi.org/10. 1007/s11199-016-0602-5

Martin, C. L., DiDonato, M. D., Clary, L., Fabes, R. A., Kreiger, T., Palermo, F., \& Hanish, L. (2012). Preschool children with gender normative and gender non-normative peer preferences: Psychosocial and environmental correlates. Archives of Sexual Behavior, 41(4), 831-847. https://doi.org/10.1007/s10508-012-9950-6

McDonald, R. P., \& Ho, M. H. R. (2002). Principles and practice in reporting structural equation analyses. Psychological Methods, 7(1), 64-82. https://doi.org/10.1037/1082-989X.7.1.64

Mehta, C. M., Hojjat, M., Smith, K. R., \& Ayotte, B. J. (2017). Associations between gender segregation and gender identity in college students. Sex Roles, 76(11-12), 694-704. https://doi.org/10.1007/ s11199-016-0685-z

Menon, M. (2011). Does felt gender compatibility mediate influences of self-perceived gender nonconformity on early adolescents' psychosocial adjustment? Child Development, 82(4), 1152-1162. https://doi.org/10.1111/j.1467-8624.2011.01601.x

Menon, M., \& Hannah-Fisher, L. (2019). Felt gender typicality and psychosocial adjustment in Indian early adolescents. International Journal of Behavioral Development, 43(4), 334-341. https://doi. org/10.1177/0165025418820669

Millsap, R. E. (2012). Statistical approaches to measurement invariance. Routledge.

Muthén, L. K., \& Muthén, B. O. (2012). Mplus version 7. Muthén \& Muthén.

Nielson, M. G., Delay, D., Flannery, K. M., Martin, C. L., \& Hanish, L. D. (2020). Does gender-bending help or hinder friending? The roles of gender and gender similarity in friendship dissolution. Developmental Psychology, 56(6), 1157-1169. https://doi.org/10. 1037/dev0000930

Pauletti, R. E., Menon, M., Cooper, P. J., Aults, C. D., \& Perry, D. G. (2017). Psychological androgyny and children's mental health: A new look with new measures. Sex Roles, 76(11), 705-718. https:// doi.org/10.1007/s11199-016-0627-9

Perry, D. G., Pauletti, R. E., \& Cooper, P. J. (2019). Gender identity in childhood: A review of the literature. International Journal of Behavioral Development, 43(4), 289-304. https://doi.org/10.1177/ 0165025418811129

Rieger, G., \& Savin-Williams, R. C. (2012). Gender nonconformity, sexual orientation, and psychological well-being. Archives of Sexual Behavior, 41(3), 611-621. https://doi.org/10.1007/ s10508-011-9738-0

Rollero, C., Peter, G., \& Tartaglia, S. (2014). Psychometric properties of short version of the ambivalent sexism inventory and ambivalence toward men inventory. TPM: Testing, Psychometrics, Meth- 
odology in Applied Psychology, 21(2), 149-159. https://doi.org/ 10.4473/TPM21.2.3

Ruble, D. N., Martin, C. L., \& Berenbaum, S. A. (2007). Gender development. In N. Eisenberg (Ed.), Handbook of Child Psychology, (Vol. 3, $6^{\text {th }}$ ed., pp. 858-932). John Wiley \& Sons. https://doi.org/ 10.1002/9780470147658.chpsy0314

Salvati, M., Pistella, J., Ioverno, S., Giacomantonio, M., \& Baiocco, R. (2018). Attitude of Italian gay men and Italian lesbian women towards gay and lesbian gender-typed scenarios. Sexuality Research and Social Policy, 15(3), 312-328. https://doi.org/10. 1007/s13178-017-0296-7

Scholte, R. H., van Lieshout, C. F., de Wit, C. A., \& van Aken, M. A. (2005). Adolescent personality types and subtypes and their psychosocial adjustment. Merrill-Palmer Quarterly, 51(3), 258-286.

Schwartz, M. D. (2014). Quantum field theory and the standard model. Cambridge University Press.

Shields, S. A. (2008). Gender: An intersectionality perspective. Sex Roles, 59(5), 301-311. https://doi.org/10.1007/ s11199-008-9501-8

Smith, T. E., \& Leaper, C. (2006). Self-perceived gender typicality and the peer context during adolescence. Journal of Research on Adolescence, 16(1), 91-104. https://doi.org/10.1111/j.1532-7795. 2006.00123.x

Spence, J. T., Helmreich, R., \& Stapp, J. (1975). Ratings of self and peers on sex role attributes and their relation to self-esteem and conceptions of masculinity and femininity. Journal of Personality and Social Psychology, 32(1), 29-39. https://doi.org/10.1037/ h0076857
Tabachnick, B. G., \& Fidell, L. S. (2013). Using multivariate statistics: International edition. Pearson.

Tam, M. J., \& Brown, C. S. (2020). Early adolescents' responses to witnessing gender-based harassment differ by their perceived school belonging and gender typicality. Sex Roles, 83(7-8), 412-425. https://doi.org/10.1007/s11199-020-01126-0

Ueno, K., \& McWilliams, S. (2010). Gender-typed behaviors and school adjustment. Sex Roles, 63(7), 580-591. https://doi.org/10. 1007/s11199-010-9839-6

Ueno, K., Roach, T., \& Peña-Talamantes, A. E. (2013). Sexual orientation and gender typicality of the occupation in young adulthood. Social Forces, 92(1), 81-108. https://doi.org/10.1093/sf/sot067

Yavorsky, J. E., \& Buchmann, C. (2019). Gender typicality and academic achievement among American high school students. Sociological Science, 6, 661-683. https://doi.org/10.15195/v6.a25

Young, R., \& Sweeting, H. (2004). Adolescent bullying, relationships, psychological well-being, and gender-atypical behavior: A gender diagnosticity approach. Sex Roles, 50(7), 525-537. https://doi.org/ 10.1023/B:SERS.0000023072.53886.86

Zosuls, K. M., Andrews, N. C. Z., Martin, C. L., England, D. E., \& Field, R. D. (2016). Developmental changes in the link between gender typicality and peer victimization and exclusion. Sex Roles, 75(5), 243-256. https://doi.org/10.1007/s11199-016-0608-z

Publisher's Note Springer Nature remains neutral with regard to jurisdictional claims in published maps and institutional affiliations. 